\title{
STORM SURGE
}

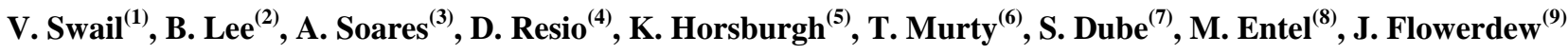 \\ (1) Environment Canada, 4905 Dufferin Street, Toronto, Ontario M3H 5T4 Canada, Email: Val.Swail@ec.gc.ca \\ ${ }^{(2)}$ Intergovernmental Oceanographic Commission of UNESCO (United Nations Educational, Scientific and Cultural \\ Organization), 1 rue Miollis, 75732 Paris Cedex 15, France, Email: b.lee@ unesco.org \\ ${ }^{(3)}$ World Meteorological Organization, 7 bis, Avenue de la Paix, Case Postale 2300, CH-1211 Geneva 2, Switzerland, \\ Email: ASoares@wmo.int \\ ${ }^{(4)}$ U.S. Army Engineer Research and Development Center, 3909 Halls Ferry Rd. Vicksburg, MS, USA, 39180-6199, \\ Email: Donald.T.Resio@usace.army.mil \\ ${ }^{(5)}$ Proudman Oceanographic Laboratory, 6 Brownlow Street, Liverpool, L3 5DA, United Kingdom, \\ Email: Kevinh@pol.ac.uk \\ (6) University of Ottawa, 161 Louis Pasteur, Ottawa, Ontario, Canada, K1N 6N5, Email: tadmurty@gmail.com \\ (7) Indian Institute of Technology, Hauz Khas, New Delhi 110 016, India, Email: skdube@ @as.iitd.ac.in \\ ${ }^{(8)}$ Bureau of Meteorology, GPO Box 1289, Melbourne, Victoria, 3001, Australia, Email: m.entel@bom.gov.au \\ ${ }^{(9)}$ Met Office, FitzRoy Road, Exeter EX1 3PB, United Kingdom, Email: Jonathan.Flowerdew@metoffice.gov.uk
}

\begin{abstract}
The $1^{\text {st }}$ JCOMM (Joint World Meteorological Organisation (WMO)/Intergovernmental Oceanographic Commission (IOC) Technical Commission for Oceanography and Marine Meteorology) Scientific and Technical Symposium on Storm Surges was held in Seoul, Korea in October 2007. This paper describes the results from the symposium, and in particular the actions and recommendations proposed for the scientific, governmental and inter-governmental organizations responsible for multi-hazard marine warning systems. These recommendations included issues related to enhancements to storm surge modelling, operational forecasting, including the development of ensemble forecasting techniques, and data issues, including both measurement and access to both in-situ and remotelysensed data sources for water level measurements and other relevant variables. The symposium spawned several activities aimed at enhancing storm surge forecasting and risk assessment, which in turn led to the set of requirements, described in this paper for MetOcean (meteorological and oceanographic) and related data in support of total water level prediction resulting from tide, wave and surge interactions, and associated inundation.
\end{abstract}

\section{INTRODUCTION}

Storm surges, and their associated coastal inundation, are major coastal hazards, in both tropical and extra-tropical areas, and are clearly among the critical natural phenomena which should be addressed by the Global Earth Observation System of Systems (GEOSS), with the aim of reducing loss of life and property in lowlying coastal areas. In this context GEO endorsed the JCOMM (Joint World Meteorological Organisation (WMO)/Intergovernmental

Oceanographic
Commission (IOC) Technical Commission for Oceanography and Marine Meteorology) Scientific and Technical Symposium on Storm Surges (SSS) [1] as a major contribution towards fulfilling the objectives of GEOSS (Global Earth Observation System of Systems) under its Disasters Theme. Coastal regions around the world are often heavily populated and their economic productivity and importance is significant. Of the 33 world cities predicted to have at least 8 million people by 2015, at least 21 are coastal, including 8 of the 10 largest, and highly vulnerable to coastal hazards including storm surges.The 1970 Bangladesh cyclone was responsible for more than 300,000 deaths, and in 2008 Cyclone Nargis became the worst natural disaster in the history of Myanmar, causing catastrophic destruction, with damage estimated at over $\$ 10$ billion and at least 146,000 fatalities. The Chittagong cyclone of April 1991 killed 140,000 people in Bangladesh. Almost all the loss of life and most of the damage from a tropical cyclone is attributable to storm surge.

Bangladesh was again battered by a major storm surge in November 2007, with thousands of houses destroyed; 650,000 villagers fled to shelters, and a significant number of fishermen were drowned. This storm was one of the strongest ever in the Indian Ocean, the equivalent of a Category 5 hurricane. The national authority, as well as many international expert groups in storm surge modelling, produced and disseminated warnings to ensure timely evacuation. As a result, the death toll was much lower than has been seen in other, less intense, storms in the region. This points to the necessity of upgrading the storm surge warning system for the countries that do not have capacity to do it. Table 1 shows a list of events with the greatest number of casualties from tropical storms. 


\begin{tabular}{|c|c|c|}
\hline Date & Location & Death Toll \\
\hline 1970 & Bangladesh (Bhola) & $300,000-500,000$ \\
\hline 1737 & India (Calcutta) & 300,000 \\
\hline 1839 & India & 300,000 \\
\hline 1881 & Vietnam (Haiphong) & 300,000 \\
\hline 1886 & China & 300,000 \\
\hline 1923 & Japan & 250,000 \\
\hline 2004 & Indian Ocean tsunami & 230,000 \\
\hline 1876 & Bangladesh (Great Backerganj Cyclone) & 200,000 \\
\hline 1897 & Bangladesh & 175,000 \\
\hline 2008 & Myanmar (Cyclone Nargis) & 146,000 \\
\hline 1991 & Bangladesh (Chittagong) & 140,000 \\
\hline 1882 & India (Bombay) & 100,000 \\
\hline 1908 & Messina Italy tsunami & 100,000 \\
\hline 1864 & India (Calcutta) & 60,000 \\
\hline 1922 & China (Swatow Typhoon) & 60,000 \\
\hline 1833 & India & 50,000 \\
\hline 1822 & Bangladesh & 40,000 \\
\hline 1883 & Indonesia tsunami (Krakatoa) & 36,000 \\
\hline 1780 & Antilles (West Indies) & 22,000 \\
\hline 1965 & Bangladesh & 19,279 \\
\hline 1999 & India & 15,000 \\
\hline 1963 & Bangladesh & 11,520 \\
\hline 1961 & Bangladesh & 11,466 \\
\hline 1985 & Bangladesh & 11,069 \\
\hline 1971 & India & 10,000 \\
\hline 1977 & India & 10,000 \\
\hline 1966 & Cuba & 7,196 \\
\hline 1900 & USA (Galveston) & 6,000 \\
\hline 1960 & Bangladesh & 5,149 \\
\hline 1960 & Japan & 5,000 \\
\hline 1972 & India & 5,000 \\
\hline 2007 & Bangladesh (Cyclone Sidr - equivalent Category-5 storm) & $3,447 *$ \\
\hline
\end{tabular}

Table 1. Deaths in tropical cyclones - most fatalities in tropical storms are due to storm surge. In italics are the three most deadly tsunami events for comparison. All casualty figures are estimates which vary widely according to source.

This paper will primarily focus on the results from the JCOMM Symposium, and in particular the actions and recommendations proposed for the scientific, governmental and inter-governmental organizations responsible for multi-hazard marine warning systems.

These recommendations included issues related to enhancements to storm surge modelling, operational forecasting, data issues including both measurement and access, development of a global storm surge database, storm surge climatology and risk assessment, and development of "best practices" and standardization for water level observations, and metadata.

The real impact on coastal areas is not from a sole reason: various factors - such as sea-level rise, increased storminess, inundation - combine and cause greater damage to low-lying coastal regions. To improve the predictability of coastal hazards, those 
various factors should be considered altogether. As mean sea levels rise by $20-90 \mathrm{~cm}$ towards the end of this century [2] storm surge issues for both real-time warning systems and risk assessment will become even more important.

The SSS made a number of wide-ranging recommendations on future requirements for development of two key activities: (1) real-time operational storm surge forecasting as a contribution to multi-hazard marine warning systems and (2) improved risk assessment. Underpinning those requirements is the need for enhanced observational data for a number of parameters on a range of temporal and spatial scales. Each of these areas will be explored in more detail in the following sections. Other important recommendations related to storm surge mitigation, but discussion of those aspects is outside the scope of this paper.

\section{STORM SURGE FORECASTING}

Storm surge modelling and forecasting approaches can range from simplistic methods which rely heavily on observational data and relationships suggested by those data, to the complex new generation of surge models where, given accurate well-resolved forcing functions to represent winds, waves, atmospheric pressure, tides and riverine flows, modellers could approach the capacity to simulate the fundamental physics [3]. Extension of the forecast beyond the magnitude of the surge itself to address critical inundation modelling and mapping issues introduces yet another level of complexity to the problem. Each level of complexity is accompanied by an increased level of observational data requirement, in terms of parameters measured, and their spatial and temporal resolution.

A concise summary of issues to be considered when developing advanced storm surge prediction models includes but is not limited to the following:

- Surge events are rare (relatively), and the associated historical data are limited.

- Forces that drive surges differ from one storm to another, and storm characteristics evolve.

- Coastal inundation risks cannot be well posed in terms of only storm frequency and intensity; storm size is also a critical factor.

- Computational solutions of the governing equations are limited by the scope and scales of the modelled physics, the modest size of the regions over which the computations are performed, and the lack of spatial resolution of critical phenomena influencing the solutions. As a result they require extensive case and region specific calibration or tuning of the boundary forcing and model parameters.

- Accurate modelling of storm surges requires an adequate specification of the geometry of the basin and continental shelf leading up to the coastal floodplain (specifically the two cross-shelf geometric factors, the depth of the water and the shelf width); shelves with a large shallow water area will produce larger surges than those with steep offshore slopes.

- Coastal geometries can be very complex both across and along the shelf. The scales of such forcing processes as are associated with wind and wave fields can range from metres in complex shallow areas to hundreds of kilometres in large deep basins.

- Ocean response models use winds averaged over 10-30 minutes at a reference height of $10 \mathrm{~m}$. Those winds are typically only about $65-75 \%$ of speeds at aircraft flight level and are further reduced to $80 \%$ of the fastest one-minute duration wind speeds reported by the aircraft. Accordingly, the hurricane wind speeds used in ocean response modelling are typically only in the range of 30-60 $\mathrm{m} / \mathrm{s}$.

- Forcing for surge generation includes momentum transfers from waves in addition to the direct transfer from winds. The flux of that momentum transfer (radiation stress), arises from a wave momentum flux divergence that is primarily related to wave breaking, and is highly dependent on the slope and depth of the sea bottom.

- Much of the structure of a hurricane wind field has been found to be well represented by a relatively small set of parameters: storm intensity, size, forward speed, and a "peakedness" function. Coastal surge models driven with best-fit parametric wind fields have systematic errors similar to models employing wind fields that are not parametrically constrained, but $10-20 \%$ higher random errors.

- Future models will need to incorporate improved knowledge of the coastal winds in hurricanes, specifically the details of the eye-wall structure and open-water wind structure changes as hurricanes approach landfall.

Other issues which are important include extremely complex effects of wind, wave and current flows through partially or fully submerged vegetation and integrated frictional effects of a wetland's complex sub-grid scale channels and distributary systems, geomorphic changes associated with hurricanes, including deepening of channels; degradation and 
breaching of barrier islands, coastal dunes and levees during the storm; and deposition of sediment during the floodwater recession. This level of complexity is beyond the scope of the present paper.

In real-time operational practice, most surge forecasting models generally fall into the mid-range described above. The high-end physics-based models are too data and computationally intensive to be run operationally virtually anywhere in the world, except possibly the US coast of the Gulf of Mexico.

Commonly-used operational surge models, hydrodynamic ocean models, such as the vertically integrated models developed at the Indian Institute of Technology and widely employed in the Indian Ocean and Arabian Sea (and elsewhere), predict only the residual storm surge at the coastline. The only meteorological inputs required for the model are the positions of the cyclone, pressure drop and radii of maximum winds at fixed time intervals.

While the residual surge is important, it is more important to estimate the total water level envelope (TWLE) at the time of cyclone landfall for issuing effective warnings in threatened areas [4]. A meaningful ensemble forecast of TWLE is better still. Total water level is the combined effect of storm surge, high tide and wave set-up, and so accurate prediction of wind waves and tidal height together with their non-linear interaction with the storm surge in the model is essential. The non-linear interaction of surge and tide may significantly modify the evolution of surges [5] and [6]. However, prediction methods for wave setup are not well established yet.

Since the evolution of storm surges near the coast is known to be very sensitive to the coastal geometry and offshore bathymetry at the location of the landfall of the cyclone, operational models should include these factors as accurately as possible. Operational centres should use models of appropriate horizontal resolution $(\sim 3 \mathrm{~km})$ for accurate prediction of the surges [7].

Tidal heights for coastal forecasts are derived from tide tables that are generated using harmonic analysis, since even at the finest resolution numerical models do not give comparable accuracy [8]; this implies that forecasters need reliable methods of arriving at tidal estimates for sites that lack long term observations. The most robust method of tidal interpolation is to use a numerical model that has been scaled by the observations [9]. Some models assimilate tidal data in the operational forecast cycle.

The most significant source of uncertainty for storm surge magnitude is the causal meteorology, specifically the wind strength and the horizontal gradients of atmospheric pressure at the sea surface.
Other contributory factors to total water level include continental shelf waves, and topographic Rossby waves, whose accurate simulation places a further demand on hydrodynamical models.

Another area that has not yet been widely considered is the estimation of the coastal stretch likely to be inundated. To achieve this, development of real-time ocean-river coupled models is required. Earlier work studied in detail the penetration of surge through rivers and its interaction with river runoff [10] and [11]; however it requires major effort and data to develop an operational system in present models. It would also be necessary to develop very high resolution coastal inundation models to estimate flooding of the low lying coastal regions in the event of storm surges. Studies may include the impact of heavy precipitation on the evolution of surge. Requirements for precipitation quantification and river flow quantification for inundation computation need to be defined.

\subsection{Ensemble surge forecasting}

The non-linearity of both meteorological and ocean models means that any deterministic forecast is strongly affected by its initial conditions, as well as choices for those parameters used to describe unresolved physical processes (e.g. momentum transfer between the atmosphere and the sea surface) [8]. Also, a single, deterministic forecast (which contains implicit error) makes it difficult to accurately determine the risk of a particular critical threshold or warning level being exceeded. Ensemble forecasting quantifies the uncertainty by making many numerical simulations using different choices of initial states and key parameters.

\section{RISK ASSESSMENT}

Risk assessment for storm surge and related inundation is based on analysis of the long term frequency, magnitude and duration of storm surge events for individual regions. This is based either on analysis of the limited historical water level records at specific measurement locations, coupled with associated post-event data derived from surveys of damage and extent of flooding, or from hindcast studies of all storm surge events affecting specific areas using the same range of storm surge models described in the preceding sections. In hindcast studies more sophisticated models may often be feasible since timeliness is not a significant factor as it is in real-time operational forecasting where the lead time for warnings is of paramount importance. However, the hindcast model approach still suffers from the same model deficiencies and the availability of appropriate input data to drive the model. 
The distribution of adjusted annual maxima was shown to be well represented by a classical Generalized Extreme Value distribution [12]. However this analysis relies on large quantities of data (30 years or more). To overcome this limitation another statistical technique of estimating return periods may be used, based on the decomposition of a sea level record into tide and residual components, which can work well on short records. On a regional or global basis this type of analysis is severely limited by the sparseness of the water level measurement network. The existing sea level measurement network coordinated under the Global Sea Level Observing System (GLOSS) program is shown in Fig. 1. This reveals large data gaps in many areas of the world. For a phenomenon such as storm surge, which is highly location-specific depending on local bathymetry and coastal geometry as well as variability of the various forcing elements, the observational network is totally inadequate to produce a reliable risk assessment on a regional basis.

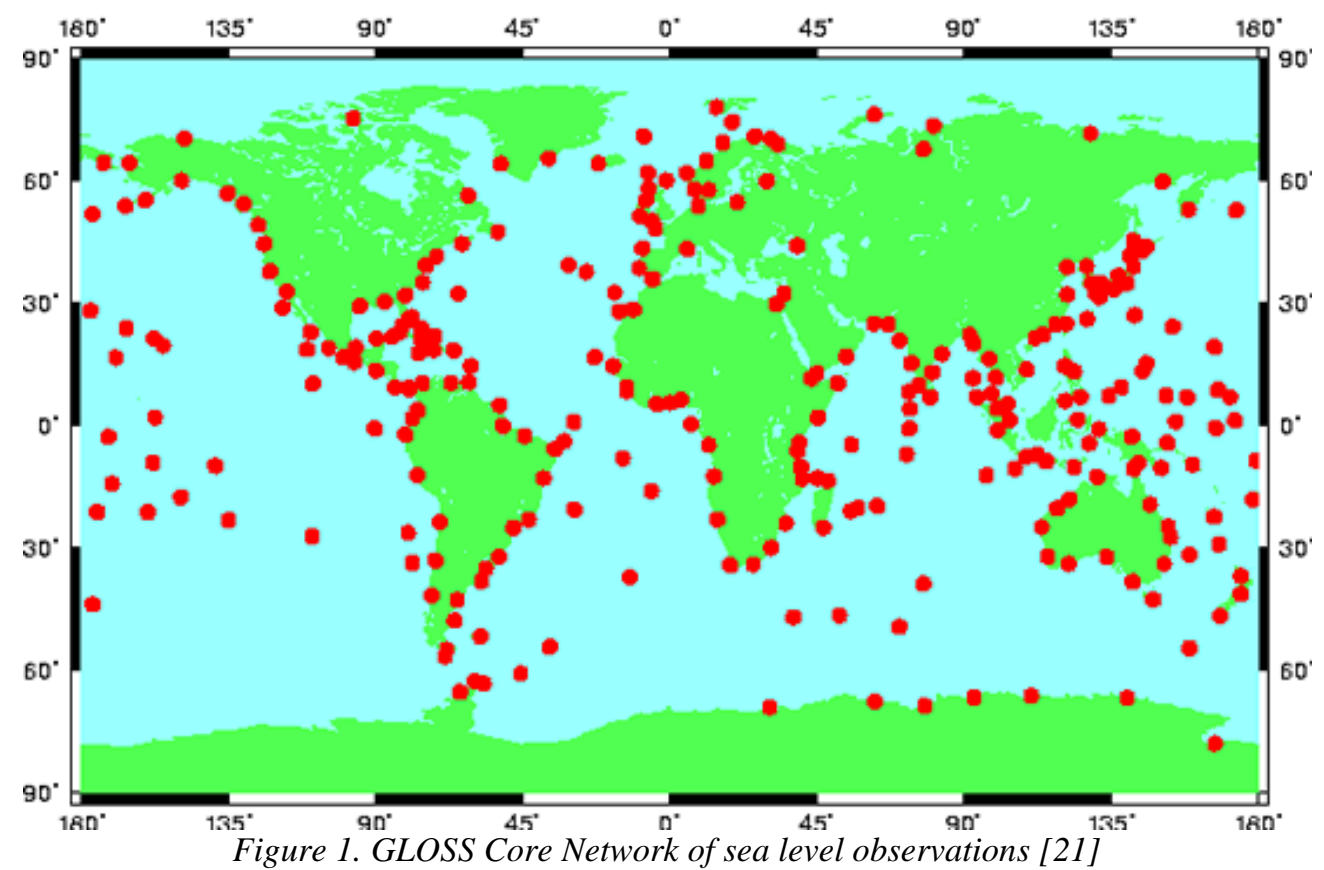

The second approach is to use techniques which have been widely used in risk assessment for ocean waves, and hindcast a long time series or events of the phenomenon. Hindcasting now forms the basis for design criteria for most offshore structures. The hindcast approach to storm surge risk assessment, both historical and future projections, has been applied for eastern Canada and southeast Australia [12] and [13].

The SSS recommended that a global storm surge climatology be developed by de-tiding the existing water level records. However, it should also be considered to develop a series of region-specific hindcast studies of storm surge to fill in the many gaps in the observational network for the purpose of risk assessment. The observation-based climatologies would provide a valuable benchmark for the hindcast results in those areas where they are available.

Another issue with respect to water level measurements, at least in the context of storm surge and risk assessment, suggested that there could be a considerable underestimation of the maximum storm surge height when 1-hour tidal records are used; hourly values would be an undersampling of anything to do with a tropical cyclone [14]. Results calculated for the maximum storm surges at two tidal stations in Korea for two typhoons, showed that the maximum surge height could differ by $50-70 \mathrm{~cm}$ for the maximum surge of $211 \mathrm{~cm}$ (Fig. 2). A proper treatment of 1-minute tidal records which contain a high frequency fluctuation is needed. 
(a) Yeosu, Typhoon Maemi

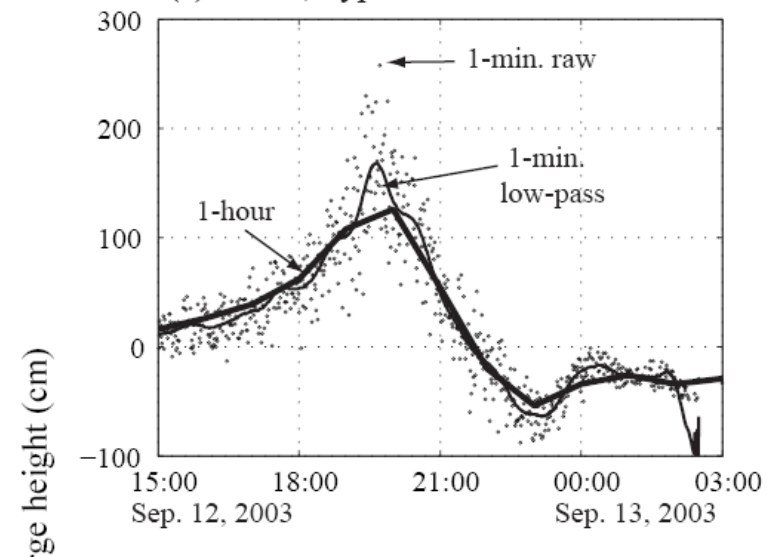

(c) Yeosu, Typhoon Ewiniar

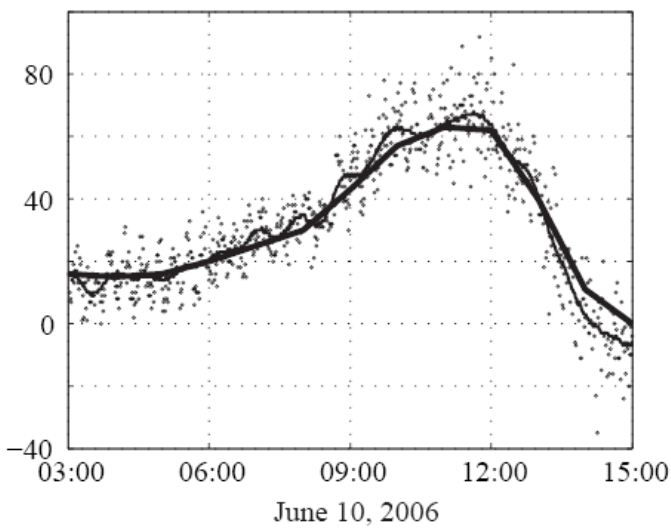

(b) Masan, Typhoon Maemi

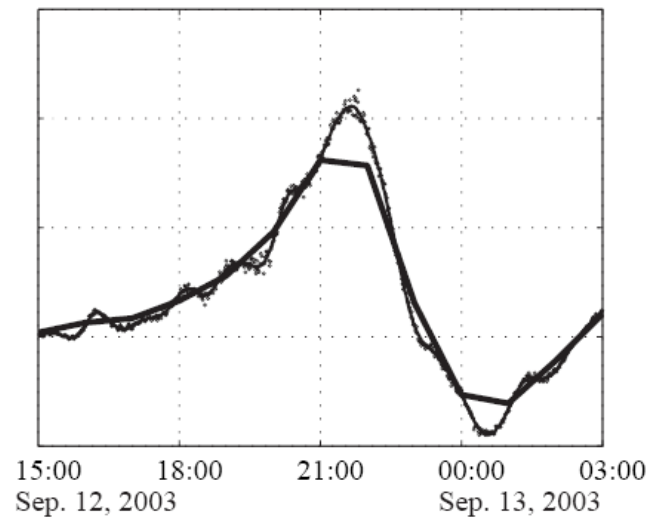

(d) Masan, Typhoon Ewiniar

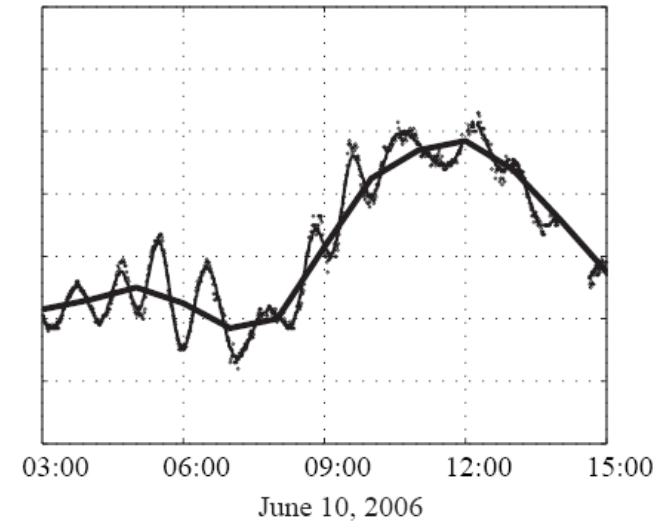

Date (LST)

Figure 2. Calculated storm surge heights during typhoons Maemi and Ewiniar (scatter points: 1-minute interval data, thick solid line: 1-hour interval data, thin solid line: low-pass-filtered 1-minute data). [14].

Risk assessment depends not only on the magnitude of the storm surge itself, but other factors such as the coastal geometry and topography, as well as hydrological contributions from associated heavy rainfall and resultant river flow. Coastal topographic data are presently not available for many storm surge prone areas. Accurate elevation data are critical to the development of improved storm surge forecasts and higher quality inundation maps, as these characteristics can influence the severity and trajectory of coastal flooding impacts. Airborne topographic and bathymetric light detection and ranging (LiDAR (Light Detection And Ranging)) can be merged with the best available elevation data to create seamless models of coastal topography and bathymetry.

\section{DATA REQUIREMENTS}

Water level and associated data are required from a number of well-documented surge episodes from a region for calibration and validation of numerical predictive models, analysis of historical events and real-time forecasting and verification of storm surges. A considerable range of meteorological, oceanographic, bathymetric, topographic, hydrological and orographic data is required and it can take several decades to collect sufficient observations for a given area [15]. In recent years with the advent of additional data types, and the increased sophistication of storm surge models, the possibilities and requirements for additional data have evolved. A schematic of the storm surge prediction process is shown in Fig. 3. 


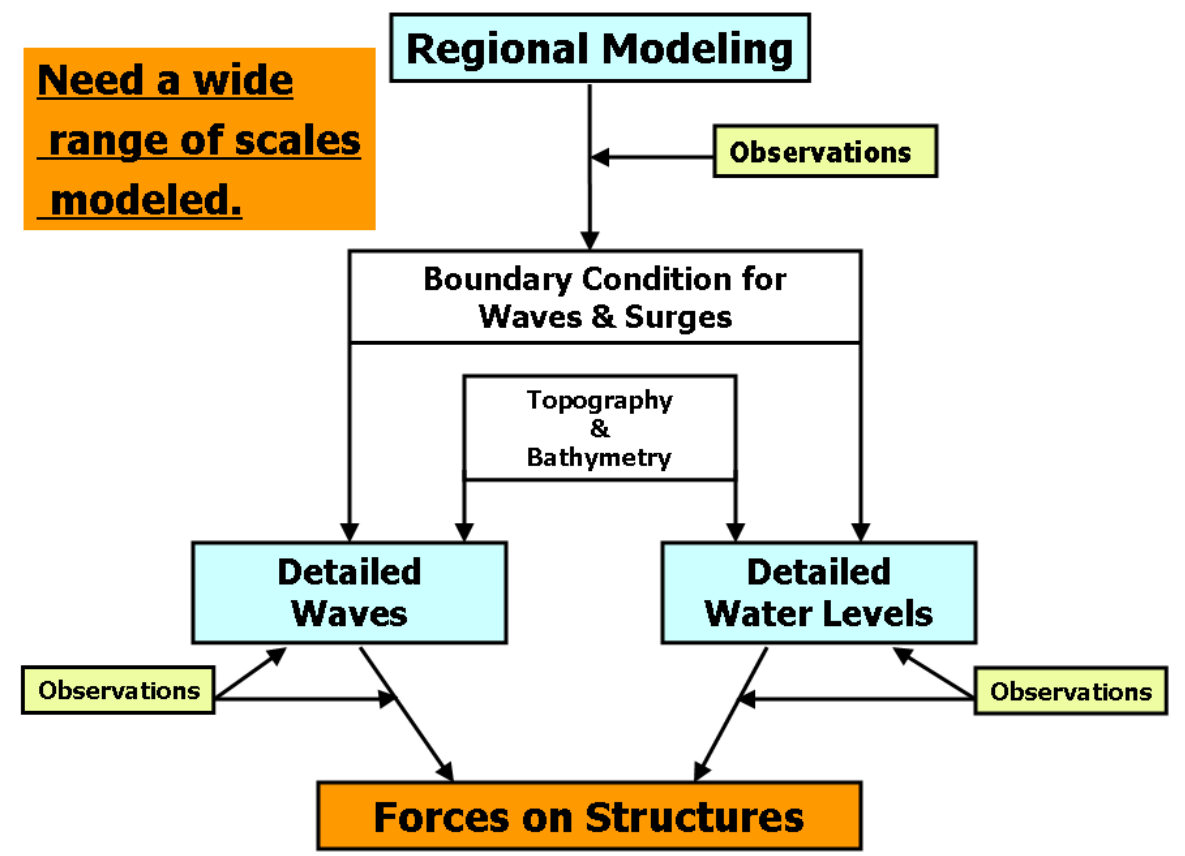

Figure 3. Schematic of data requirements for total water level predictions.

Some specific considerations for data requirements have been identified by [15]:

- Adequate benchmark information is required for the reduction of water levels to a common datum; at present, the datums used in topographic and hydrographic surveying are different.

- Normally, bathymetry and coastal geometry do not alter significantly during a surge event, but depths and shorelines change substantially on some coasts in just a few years owing to erosion and sedimentation. Rapidly changing areas should be regularly resurveyed.

- Estimated river discharge should be regularly monitored during the flooding season.

- Satellite and aircraft photos can play a very valuable role in determining the extent of flooding due to surges.

- A surge leaves a variety of marks and traces in the area it invades. Some of these effects are very short-lived; others do not become apparent until days after the flood waters retreat.

- The global distribution of permanent tide gauges is quite sparse and the probability is slight that a cyclone makes landfall close to a gauge site; if it does, there is a considerable likelihood that the gauge will be destroyed, will malfunction or exceed its range. However, records from gauges some distance along the coast in both directions can be extremely useful for indicating the coastwise extent of the surge and for verifying evaluations of past surges.

- Good estimates of the spatial distribution of the inundation following a surge may ultimately be the only reliable approach to estimating the actual maximum surge heights reached along the shoreline.

- No restrictions should be placed on the availability of water level and related data; complete documentation of a storm surge may require extensive cooperation between neighbouring countries.

\subsection{Data requirements identified by SSS}

The SSS highlighted that improvements in storm surge forecasts and products are dependent on higher resolution data, both spatially and temporally, for more parameters, encompassing not only the oceanographic aspects, but also hydrographical, topographical, hydrological as well as meteorological.

The SSS produced a detailed summary of conclusions and recommendations in the areas of (1) future research and development; (2) research to operations; (3) observations and data [1]. The key recommendations regarding data requirements and related modelling issues are summarized below.

- Improved physics and physical processes in the models; e.g. wave/current and wind/current interactions 
- Development of fully coupled basin/coastal/tide/wave/atmosphere models and programme for continuous improvement

- Improvements in total water level predictions as a result of wave set-up, wave run-up, tide and surge, as well as ocean-river coupling.

- Coupled hydrologic, hydraulic and surge models for inundation

- Enhanced and expanded use of ensemble modeling techniques

- More research, including case studies, to understand the cause of deviations from normal predictions and forecast failures, such as the sharp structural and intensity changes/variability in tropical cyclone (TC) wind fields

- Improvements in wind field analyses and forecasting (including TC track and intensity forecasts)

- Improved boundary layer specification over water and land

- More effective cooperation of meteorologists, oceanographers, coastal and ocean engineers and hydrologists

- Appropriate resolution models, based on sensitivity assessments and subject to data availability and requirements

- National access to, or development of, high resolution, near shore, bathymetric data sets

- Better altimetry in the coastal zone for surge model validation and data assimilation

- Need to take advantage of the wind products generated by satellites

- There is potential for use of HF (High-Frequency) radars

- Space agencies should contribute to high resolution bathymetric and coastal zone topographic data for better storm surge and coastal inundation forecasts

- In-situ data requirements for storm surge models and operational forecasting including inundation should be documented

- Satellite earth observation data requirements for storm surge modeling and forecasting; e.g. scatterometer, ASAR (Advanced Synthetic Aperture Radar), altimeter, nearshore, should be documented

- Assessment and evaluation of the accuracy and value of satellite data for storm surge and wave modeling and forecasting
- Assess value and practicability of other remote sensing; e.g. airborne LIDAR, HF radar

- Monitor coastal flooding by remote sensing

- Enhanced GLOSS network, with recommended 1minute sampling

- Global access to existing storm surge data sets is essential

- Very accurate meteorological forecasting is required since small spatial variations can impact surges dramatically.

- Enhance in-situ networks for all relevant variables, including higher time resolution.

- In water bodies in high latitudes, ice cover is important.

\section{SUMMARY OF DATA REQUIREMENTS AND INTERACTIONS WITH OTHER PROGRAMS}

As noted above, data requirements for storm surge forecasting and risk assessment fall into three main categories, and encompass several different variables and observational methods:

5.1 Data we need in advance of a storm surge event, which need to be updated on longer time scales.

This includes shoreline geometry, bathymetry and coastal elevation. These data are a common requirement with the tsunami forecasting and inundation activities.

- Bathymetry on continental shelf areas should be available on a horizontal resolution of $100 \mathrm{~m}$, with a vertical resolution of $1 \mathrm{~m}$, and be updated every 5 years, with more frequent updates in sensitive river mouth areas such as Bangladesh.

- Digital elevation data for coastal areas should be available with a horizontal resolution of $5 \mathrm{~m}$, a vertical resolution of $0.5 \mathrm{~m}$, and be updated on a decadal time scale.

5.2 Data we need after the event for model and forecast validation and calibration.

This is comprised of post-event surveys of inundation extent, depth and duration. This should include crest gauges or ribbon networks (specially treated ribbons which indicate exposure to flood water, deployed in advance of a storm), satellite photos of inundated regions, and manual surveys of inundated areas, with in-person interviews. This information should be collected over periods ranging from a few hours after the storm to several days depending on the rate of 
retreat of the water. The required horizontal resolution for this information is $25 \mathrm{~m}$; satellite images may be able to provide information at $10 \mathrm{~m}$ resolution. This is also a common requirement with the tsunami community for extent of tsunami inundation.

5.3 Data we need during the event, over the period of a few days preceding landfall of a storm (tropical or extratropical), updated in real time.

This can generally be characterized as MetOcean data, including the meteorological forcing and the water level response. These data would include:

- storm track and intensity,

- nearshore wind fields,

- wave heights,

- surface water levels (at least 1-minute average values),

- surface pressure fields, at least pressure drop

- surface currents,

- sea surface temperature, vertical temperature profiles, sea surface height anomalies.

These data may be provided from a range of observational systems, most notably:

- satellite altimeter (winds, waves, water levels),

- scatterometer (wind),

- Synthetic Aperture Radar (winds and waves),

- tide gauges (nearshore and offshore),

- MetOcean buoys (nearshore and offshore),

- dropsondes,

- HF radar,

- Doppler radar,

- Numerical weather prediction (NWP) and parametric models, ensemble models,

- shoreline weather observations

- manned and unmanned aircraft observations

The data identified in paragraph (3) above are the ones most relevant to an operational MetOcean ocean observing program. They are also common to many other programs, so there is a large degree of commonality in terms of the data requirements and accuracy.

Requirements for accuracies of the MetOcean parameters needed are basically as given by WMO [16], although the spatial resolutions required for storm surge forecasting will be of higher resolution, at least in the shelf areas.

For storm surge modelling and forecasting, the most important period is the 12 hours immediately before landfall, and the most important area is over the continental shelf. This is where the concentration of observations and model resolution has the most impact.

Storm track and intensity information is required on a 6-hourly interval. As noted in the SSS, for tropical storms, an accurate 3-day warning requires a track forecast accurate to 75 nautical miles, while typical accuracies are presently on the order of 150 nautical miles (Fig. 4). Tropical storm intensity forecasts have not much improved in the past two decades. The data requirements and research necessary to improve tropical cyclone intensity forecasts, including hydrographic and satellite-derived observations are described by [17]. The sea surface temperature and the upper ocean meso-scale and its vertical thermal structure may be key features in tropical cyclone intensification. Satellite altimeter observations of the sea height anomaly are considered to generally reflect the subsurface thermal conditions. In high gradient regions, SST and heat content data may be required on scales of the order of $1 \mathrm{~km}$

An important potential data set for storm surge prediction would be from satellite altimeter, particularly in the areas near the coast. The possibilities of extending the capabilities of current and future altimeters as close as possible to the coast, with the ultimate aim to integrate the altimeterderived measurements of sea level, wind speed and significant wave height into coastal ocean observing systems are described by [18]. They note that "the quintessential, most immediate application of coastal altimetry is to look at the coastal sea level, including short term sea level variations (leading to monitoring of surges)". Several parameters derived from altimetry can contribute to forecasts of tropical cyclone paths, including wind speed and wave height, meso-scale circulation and the tropical cyclone heat potential, as well as improvement of tide knowledge by direct assimilation of the data into hydrodynamic models [19].

Surface wind data from satellite, especially scatterometer, will play an important role in defining the forcing for storm surge generation, from both tropical and extra-tropical storms. Research requirements for remotely sensed winds (and waves) include calibration issues in the most extreme conditions, and rain attenuation effects, which will be critical in tropical cyclones [20]. 


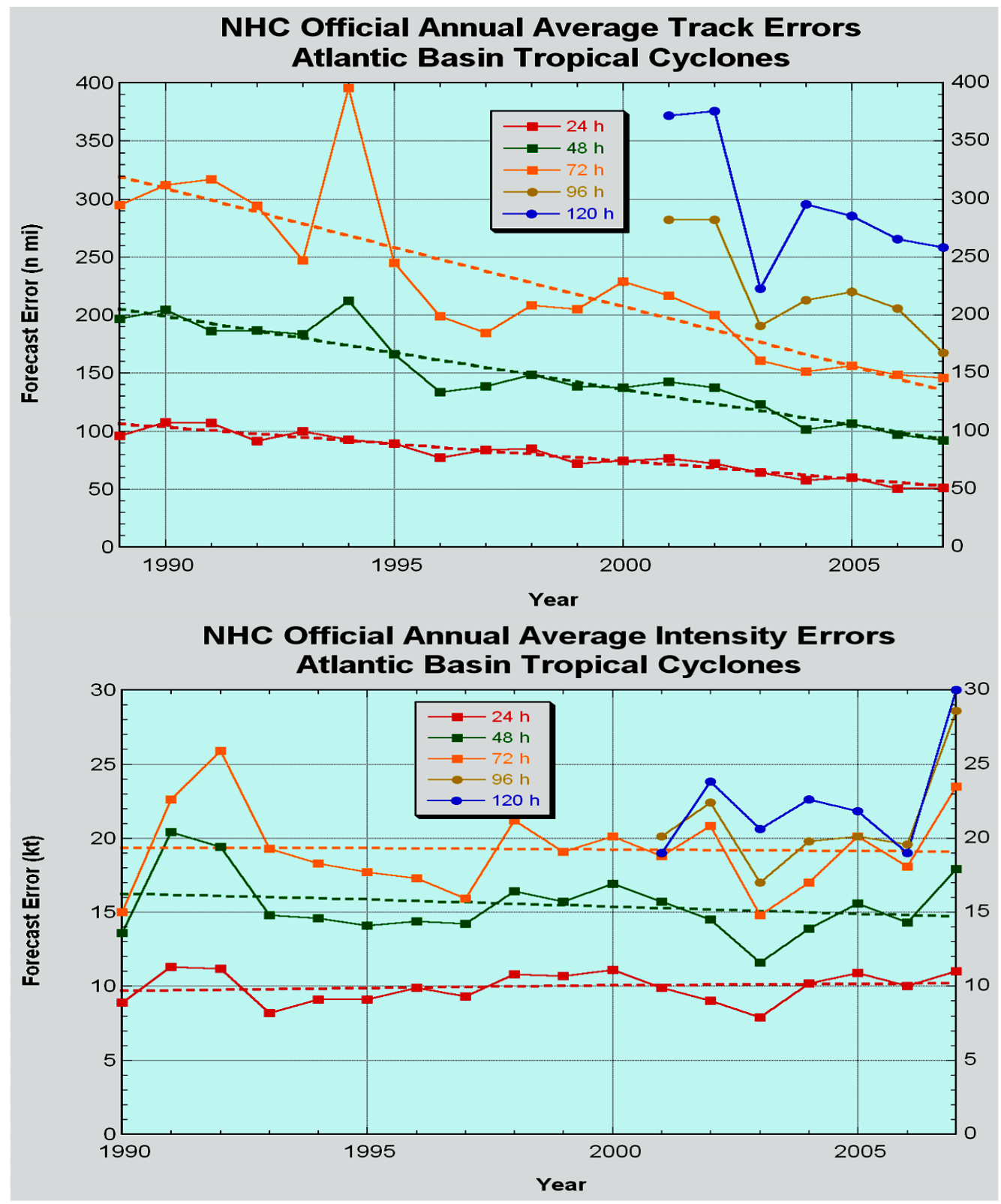

Figure 4. Annual average errors in track (upper) and intensity (lower) for Atlantic Basin tropical cyclones

GLOSS (Global Sea Level Observing System) has sought to provide water level data that meets the requirements of both the tsunami and the storm surge community [21], with more data now available in nearreal time, e.g. 166 of the GLOSS Global Core Network stations as opposed to 72 a decade earlier. Real time sea level data are also available from the University of Hawaii Sea Level Center and the IOC (International Oceanographic Commission) and Flanders Marine Institute; there is a sense that GLOSS should serve as the central data assembly and archiving center for all high quality tide gauge datasets that are freely available. The sea level data generally meet the accuracy requirements of storm surge forecasting, although the geographical coverage is still less than optimal.
Numerical models of atmosphere and ocean play a critical role in storm surge prediction, since the resolution required in MetOcean forcing and evolution of the surge as it approaches the coast is considerably higher than that provided by most observational systems. Nevertheless, it is the observation and model combination that provides the best results. Meso-scale models are typically run on resolutions of 1-2 km over the shelf, with outputs at 15 minute intervals. For comparison, most in-situ measurements are hourly at best, at considerably coarser spacing; the double resolution mode QuikSCAT (Quick Scatterometer Satellite) observations are at a resolution of $14 \mathrm{~km}$. Of course many of the simpler existing operational tropical cyclone surge models still require only the central pressure drop and the radius of maximum winds. 


\section{THE FUTURE}

Both the $61^{\text {st }}$ Session of the World Meteorological Organization Executive Council and the $41^{\text {st }}$ Session of the Intergovernmental Oceanographic Commission Executive Council 41 endorsed the recommendations of the JCOMM SSS and encouraged Members/Members States to actively contribute to these activities in support of improved global forecasting of storm surges and risk assessment.

Subsequently, planning has been taking place with respect to integrated forecast enhancement, in the development of one or more Demonstration Projects for a Storm Surge Watch Scheme to include storm surge model enhancement, integration with other disciplines, including in particular hydrology, to improve storm surge forecasting capability, including inundation forecasts, with the underpinning requirement of increased data resources to support these activities.

Outcomes have recently been derived from an advisory Workshop on enhancing forecasting capabilities for North Indian Ocean storm surges under the framework of the UNESCO (United Nations Educational, Scientific and Cultural Organization) project on "Enhancing regional capabilities for coastal hazards forecasting and data portal systems" [22]; and a European Space Agency (ESA Storm Surge Project) project [23] to look at how storm surge forecasting systems and applications can be improved through the innovative use of ocean, land and atmospheric satellite observations. One common goal from all of these coordinated activities will be to comprehensively define a set of data requirements, both in-situ and remotely sensed. Broad support for these important initiatives is essential to improve our understanding and prediction of the most destructive phenomenon in the marine environment.

\section{REFERENCES}

1. JCOMM (2008). Proceedings of the $1^{\text {st }}$ JCOMM Scientific and Technical Symposium on Storm Surges, Seoul, Republic of Korea, 2-6 October 2007. JCOMM Technical Report No. 44, WMO/TD-No. 1442. Geneva, Switzerland. (http://www.surgesymposium.org)

2. IPCC (2007). Climate Change 2007: Synthesis Report. Contribution of Working Groups I, II and III to the Fourth Assessment Report of the Intergovernmental Panel on Climate Change [Core Writing Team, Pachauri, R.K and Reisinger, A. (eds.)]. IPCC, Geneva, Switzerland, $104 \mathrm{pp}$.

3. Resio, D.T. and Westerink, J.J. (2008). Modeling the physics of storm surges. Physics Today. September 2008, 33-38.
4. Jain Indu, A D Rao, V Jitendra and S K Dube, "Computation of expected total water levels along the east coast of India", Journal of Coastal Research:, 681687. 2010, doi:10.2112/08-1170.1.

5. Johns, B., Rao, A. D., Dube, S. K. and Sinha, P. C. (1985). Numerical Modelling of the tide surge interaction in the Bay of Bengal. Phil. Trans. Roy Soc. London A 313, 507-535.

6. Sinha, P. C., Jain, I., Bhardwaj, N., Rao, A. D. and Dube, S. K. (2008). Numerical Modeling of Tide-Surge Interaction along Orissa coast of India. Natural Hazards, 45: 413-427.

7. Dube, S. K., Chittibabu, P., Sinha, P. C., Rao, A. D. and Murty, T. S. (2004). Numerical modeling of storm surges in the head Bay of Bengal using location specific model. Natural Hazards 31, 437-453.

8. Horsburgh, K. J., and Flowerdew, J. (2009). Real time coastal flood forecasting. In: Applied uncertainty analysis for flood risk management. Editors K. Beven and J. Hall. World Scientific Press. (in press).

9. Dixon, M. J. and Tawn, J. A. (1995). Extreme sea-levels at the UK A-class sites: optimal site-by-site analyses and spatial analyses for the east coast. Proudman Oceanographic Laboratory, Internal Document, No 72, 298 pp.

10. Dube, S. K., Sinha, P. C. and Roy, G. D. (1986). The effect of continuously deforming coastline on the numerical simulation of storm surges in Bangladesh. Math. Comput. Simul. 28, 41-56.

11. Dube, S. K., Sinha, P. C., Rao, A. D., Jain, I. and Agnihotri, N. (2005). Effect of Mahanadi river on the development of storm surge along the Orissa coast of India: A numerical study. Pure and appl. geophys 162, 1673-1688.

12. Thompson, K. R., Bernier, N. and Chan, P. (2009). Extreme Sea Levels, Coastal Flooding and Climate Change With a Focus on Atlantic Canada. Numerical modelling of Storm Surges--- the latest developments. Natural Hazards Special Issue (Val Swail, Shishir Dube, Paula Etala, Kevin Horsburgh, eds.) 51 (1), 139150.

13. McInnes, K. L., Macadam, I., Hubbert, G.D. and O'Grady, J.G. (2009). A Modelling Approach for Estimating the Frequency of Sea Level Extremes and the Impact of Climate Change in Southeast Australia. Numerical modelling of Storm Surges--- the latest developments. Natural Hazards Special Issue (Val Swail, Shishir Dube, Paula Etala, Kevin Horsburgh, eds.) 51 (1), 115137.

14. Lee, J.C., Park, K.-S., Kwon, J.-I. and. Kim, S.-I. (2009). Storm surge calculations using sea level data. Storm surges around the globe - the operational aspects Marine Geodesy Special Issue (T.S. Murty, V.R. Swail, J.W. Seo, eds.), 32 (2), 108-117.

15. Henry, R.F. and Murty, T.S. (1990). Relevance of Data Dossiers for Storm Surge Prediction. Natural Hazards, 3, 413-417. 
16. World Meteorological Organization, Rolling Review of Requirements and Statements of Guidance, in (http://www.wmo.int/pages/prog/sat/RRR-andSOG.html)

17. Goni, G. \& Co-Authors (2010). "The Ocean Observing System for Tropical Cyclone Intensification Forecasts and Studies" in these proceedings (Vol. 2), doi:10.5270/OceanObs09.cwp.36

18. Cipollini, P. \& Co-Authors (2010). "The Role of Altimetry in Coastal Observing Systems" in these proceedings (Vol. 2), doi:10.5270/OceanObs09.cwp.16

19. Wilson, S. \& Co-Authors (2010). "The Ocean Surface Topography Constellation: The Next 15 Years in Satellite Altimetry" in these proceedings (Vol. 2), doi:10.5270/OceanObs09.cwp.92

20. Bourassa, M. \& Co-Authors (2010). "Remotely Sensed Winds and Wind Stresses for Marine Forecasting and Ocean Modeling" in these proceedings (Vol. 2), doi:10.5270/OceanObs09.cwp.08

21. Merrifield, M. \& Co-Authors (2010). "The Global Sea Level Observing System (GLOSS)" in these proceedings (Vol. 2), doi:10.5270/OceanObs09.cwp.63

22. Lee, B. and Dube, S. (2009). Advisory Workshop on enhancing forecasting capabilities for North Indian Ocean Storm Surges, 14-17 July 2009. IOC Workshop Report No. 223, Paris, UNESCO, 37pp. (www.jcomm.info/SSIndia).

23. ESA. (2009). Report of the ESA Storm Surge Consultation Meeting, San Servolo Island, Venice, Italy, 17-18th September 2009. 